\title{
COMPOSIÇÃO CORPORAL, NO 19 ESTRO, DE RATAS SUBMETIDAS A DIFERENTES GRAUS DE RESTRIÇÃO ALIMENTAR
}

\author{
Leda Ulson Mattos* \\ Hisako Kajiyama* \\ Sandra Megrich*** \\ Margareth Knoch*** \\ Ruth Silvia Steuer***
}

MATTOS, L.U.; KAJIYAMA, H.; MEGRICH, S.; KNOCH, M.; STEUER, R.S. Composição corporal, no 1 ? estro, de ratas submetidas a diferentes graus de restriçăo alimentar. Rev. Esc. Enf. USP. São Paulo, 18(3):215-221,1984.

As autoras estudaram a composição corporal em proteina, água e gordura, em $2 \mathrm{gru}$ pos de ratas com restrição alimentar, que recebiam, respectivamente, $6 \mathrm{~g}$ dia e $4 \mathrm{~g}$ dia de uma dieta com $20 \%$ de proteina de caseina. Como percentagem de pesa corporal houve aumento do teor de proteina e diminuição de água e de gordura nos grupos com restrição) alimentar, em relação ao grupo controle. Na época do 19 estro a média ponderal não diferia, significativamente, nos 3 grupos.

\section{INTRODUÇÃO}

Estudos de KENNEDY \& MITRA (1963) mostraram que a puberdade do rato era alcançada quando este atingia determinado peso. Estes dados foram usados por FRISCH \& REVELLE (1970), FRISCH \& REVELLE (1971), FRISCH (1972), FRISCH (197²) para construir um modelo semelhante em seres humanos.

A antecipação de menarca em adolescentes bem nutridos, nos Estados Unidos, foi uma das observações que FRISCH (1972) utilizou como suporte para a hipótese de que um "peso crítico", ou melhor, um certo grau de gordura é necessário para atingir a puberdade (FRISCH \& McARTHUR, 1974).

* Química. Professor Titular do Departamento de Enfermagem Médico Cirúrgica da Escola de Enfermagem da USP - disciplina Nutrição e Dietética Aplicadas à Enfermagem.

* Enfermeira. Mestre em Enfermagem. Professor Assistente do Departamento de Enfermagem Materno-Infantil e Psiquiátrica da EEUSP - disciplina Enfermagem Ginecológica e Obstrétrica e Neonatal.

*** Estudante do Curso de Graduação em Enfermagem da Escola de Enfermagem da USP. 
Durante o amadurecimento do sistema reprodutor, o corpo modifica-se, não só em proporções, como também em relação à composição corporal (WIDDOWSON \& Mc CANCE, 1960). Um aspecto fundamental dessa modificação é a alteração do teor de água, proteína e gordura corporal, que se acelera no pico do crescimento do adolescente (FRISCH et alii, 1973; FRISCH \& REVELLE, 1973; FRISCH, 1976). Na mulher o teor de água diminui à medida que cresce e a gordura aumenta em percentagem (EDELMAN et alii, 1952). $\mathrm{Na}$ época da maturidade a mulher tem 52\% de água e 26 a $28 \%$ de gordura (FRISCH, 1980).

A descoberta de que o início da puberdade e a manutenção da função menstrual exigem um peso crítico implica em que determinada relação gordura/peso corporal é importante para a capacidade reprodutora.

As atletas que fazem treino muito pesado tem alto índice de amenorréia. Estes resultados são interessantes porque no atleta a relação peso/altura é representada principalmente por massa muscular e pouca gordura (PARISKOVA, 1963).

Como o ciclo menstrual cessa em mulheres com desnutrição crônica ou perda rápida de peso, não é de surpreender que na jovem a desnutrição atrase a menarca (FRISCH, 1972).

FRISCH et alii (1973), tendo encontrado casos de menarca em jovens de diferentes pesos e alturas, analisou o peso em termos de composição corporal, baseado no fato de que o total de água e a massa magra estão mais correlacionadas com a velocidade metabólica do que com o peso.

Como a aromatização do andrógeno e estrógeno ocorre no tecido adiposo da mulher, parece que este tecido é importante na fonte estragonodal de estrógeno (NIMROD, 1975).

Sendo o estudo de peso, teor de gordura na puberdade de especial interesse, em virtude dos resultados encontrados em mulheres adolescentes, de que um peso crítico (FRISCH \& REVELLE, 1971) representado por um nível crítico de gordura (FRISCH, 1974, FRISCH et alii, 1973) está relacionado com a menarca e a manutenção do ciclo ovulatório (FRISCH \& McARTHUR, 1974), optamos por estudar a influência de diversos regimes alimentares sobre o início da puberdade. Para isso, estudamos a composição corporal, no 1 \% estro, de ratas recebendo dietas restritas, em quantidade de alimento, e nos propusemos verificar se, para esses grupos, é válida a hipótese de KENNEDY (1969), de que o teor de gordura armazenada é um sinal para o início da puberdade. 


\section{MATERIAL E MÉTODO}

Como animais de experiência foram utilizados 45 ratos (Rattus norwegicus, albinus, Wistar) fêmeas logo após o desmame, que se deu aos 21 dias, criadas no biotério da Escola de Enfermagem da USP. Manteve-se a temperatura ambiente entre 24 e $26^{\circ} \mathrm{C}$ e as luzes apagadas das $18 \mathrm{~h}$ às $7 \mathrm{~h}$ da manhã seguinte. Os animais desmamados foram colocados em gaiolas individuais e subdivididos em 3 grupos - Grupo C - recebendo dieta ad libitum (Tabela 1) e os Grupos I e II recebendo, respectivamente, $6 \mathrm{~g}$ e $4 \mathrm{~g}$ da mesma dieta. Os animais foram pesados e observados diariamente para se verificar se havia ocorrido abertura da vagina. Após a abertura da vagina, foi colhido material vaginal, diariamente, para determinar o 1? estro (aparecimento de células epiteliais completamente corneificadas).

No dia do 1 ? estro, após um período de $24 \mathrm{~h}$ de jejum, as ratas foram sacrificadas por anestesia com éter e pesadas. As carcassas, cortadas em pedaços colocados sobre papel alumínio, foram secas a $95^{\circ} \mathrm{C}$, até atingirem peso constante.

O peso perdido foi tomado como água total.

A carcassa seca foi então moída e foram utilizadas alíquotas para determinação da gordura, pelo método de extração com éter e do Nitrogênio total, pelo método de Kjeldahl. A proteína foi calculada multiplicando-se o teor do Nitrogênio por 6, 25.

TABELA 1 - Composição percentual das dietas utilizadas.

Componentes

$\mathrm{g} / 150 \mathrm{~g}$ de dieta

Caseína

26,8

Amido

Óleo de Algodão

40,8

Óleo de Fígado de Bacalhau

6,0

Mistura de Sais Minerais

1,6

Mistura de Vitaminas

3,6

Açúcar

1,6

20,0 


\section{RESULTADOS}

$\mathrm{Na}$ tabela 2 colocamos os dados correspondentes ao peso úmido, percentagem de água, proteína e gordura em relação ao peso corporal úmido, e gordura como percentagem do peso corporal seco, no 1 . estro.

Tabela 2 - Peso úmido, percentagem de água, proteína e gordura em relação ao peso úmido, gordura em relação ao peso seco, idade, em dias, no 1 . estro. Idade e peso dos animais no dia da abertura da vagina.

Grupos

Idade (dias)

Peso úmido

(g)

\section{ESTRO}

Idade (dias)

Peso úmido

(g)

Proteína

(g \% P. Corp. úmido)

Água

(g\% P.Corp.)

Gordura

( $\mathrm{g} \%$ P. Corp. úmido)

Gordura

(g \% P. Corp. seco)
Controle

II

$\begin{array}{rl}76,0 & \mathrm{p}<0,001^{*} \\ \pm 5,0 & \mathrm{p}<0,001^{* *} \\ 59,3 & \text { NS* }^{*} \\ \pm \quad 6,8 & \text { NS** }^{* *}\end{array}$

$36,7 \mathrm{p}<0,002^{*}$

NS*

59,0

$\pm 4,0$

$\pm 6,8 \quad \mathrm{NS}^{* *}$

NS Não significativa

* Diferença entre os grupos I ou II e o controle

** Diferença entre os grupos I e II

Os resultados da Tabela 2 foram computados, usando-se apenas os dados dos animais cuja idade estava abaixo da média das idades no 1 ? estro, nos diferentes grupos. As médias encontradas para os grupos Controle, I e II foram, respectivamente, 32,2 dias, 60,1 dias e 112,6 dias e correspondem aos 
animais que alcançaram o 1 . estro mais cedo. Gs dados dos animais que atingiram o 1. estro com idade superior a média, isto é, os que alcançaram o 1. estro tardiamente não foram usados em virtude de constituirem um número reduzido de animais, com valores muito açima da média.

O primeiro estro ocorreu, simultaneamente com a abertura da vagina em $90 \%$ do grupo controle, $20 \%$ do grupo I e $0 \%$ do grupo II.

\section{DISCUSSÃO}

Embora a composição corporal de adolescentes seja determinada indiretamente (CRAWFORD \& OSLER, 1975; FRISCH \& McARTHUR, 1974), é ela a base para a hipótese de FRISCH (1974) de que a composição corporal é o ponto crítico para o início da puberdade.

Em animais, a composição corporal é determinada por análises laboratoriais e o tipo e a distribuição da dieta são estabelecidos em cada pesquisa realizada, o que facilita o estudo.

A composição corporal e o metabolismo podem ser afetados pelo tipo de alimento ingerido e pela distribuição e horário da alimentação. Em nosso trabalho, os animais receberam quantidades restritas de alimentos, mas como a quantidade era pequena, eles ingeriram todo o alimento de uma só vez, no período da manhã. Isto contraria os costumes dos ratos que comem muitas vezes ao dia, um pouco de cada vez e são, principalmente, animais noctívagos.

Não podemos dizer que os nossos resultados comprovem a teoria de FRISCH (1974), mas nos fornecem dados sobre o efeito da restriçăo alimentar na maturação sexual. Não encontramos diferença significativa de peso entre os 3 grupos no 1 ? estro, porém, proporcionalmente à idade, as ratas dos grupos I e II pesavam menos.

$\mathrm{O}$ fato das ratas apresentarem o mesmo peso médio no 1 ? estro, nos 3 grupos, já havia sido observado por MATTOS et alii (1984) em ratas com diferentes graus de restrição e por KENNEDY \& MITRA (1963) em ratas desnutridas; FRISCH (1972) havia demonstrado em adolescentes desnutridas, que estas, embora alcançassem a menarca com 2 anos de atraso em relação ao grupo de adolescentes bem nutridas, tinham o mesmo peso.

Os resultados por nós obtidos estão em consonância com a hipótese de que populações de idades médias diferentes atingem a puberdade com um "peso demográfico" crítico constante (WILEN \& NAFTOLIN, 1976).

A baixa proporção de gordura pode refletir o uso excessivo do tecido adiposo para a manutenção do balanço energético. $\mathrm{O}$ aumento da proporção de proteína total sugere a adaptação dos animais a uma proporção reduzida de 
gordura, aumentando a massa metabólica ou proteína corpora' para um nível suficientemente alto a fim de manter o metabolismo basal (WILEN \& NAFTOLIN, 1978). A diminuição do teor de gordura leva a uma queda da energia armazenada e do isolamento corporal.

Como podemos ver na tabela 2 , há uma diferença não muito significativa no teor de proteína entre os grupos com restrição alimentar e o controle; porém, dentro de cada grupo, a proporção de proteína é constante e aumenta com o aumento da restrição alimentar, embora a diferença não seja significativa.

Observamos, ainda, uma diminuição do teor de água no grupo mais restrito, quando comparado com o grupo controle e com o de menor restrição alimentar. No regime de distribuição de alimentos por nós adotado, parece que o mesmo peso corporal é atingido com diferentes composiçðes corporais de gordura, proteína e água, não comprovando a hipótese de que o teor de gordura armazenada é um sinal para início da puberdade em ratas bem nutridas e com restrição alimentar.

\section{CONCLUSÕES}

$\mathrm{Na}$ época do 1 ? estro, apesar das ratas com restrição alimentar serem mais velhas do que as do grupo controle e, proporcionalmente à idade, mais magras, atingiram o mesmo peso corporal, maior teor de proteína, e menor de gordura e água.

O primeiro estro foi simultâneo à abertura da vagina em $90 \%$ dos animais do grupo controle, em $20 \%$ dos do grupo I e em $0 \%$ dos do grupo II.

MATTOS, L.U.; KAJIYAMA, H.; MEGRICH, S.; KNOCH, M.; STEUER, R.S. Body composition of feed-restricted female rats, at the first estrus. Rev. Esc. Enf. USP, São ) Paulo, 18(3): 215-221,1984.

At first estrus the feed-restricted rats were older and, proportionally to the age, lea-. ner than the well fed animals. They had attained a greater proportion of protein and lesser proportion of water and fat; however the animals of the two restricted diet groups: and the well fed group had the same weight.

First estrus was simultaneous with vaginal opening in $90 \%$ of the well fed animals, in $20 \%$ of the group I and in $0 \%$ of the group II. 


\section{REFERE̊NCIAS BIBLIOGRÁFICAS}

CRAWFORD, J.D. \& OSLER, D.C. Body composition at menarche the FRISCH-REVELLE hypothesis revisited. Pediactrics, Springfield, 50:449, 1975.

EDELMAN, I.S. et alii. Further observations on total body water I - Normal values throught the life span. Surg. Gynec. Obstet., Chicago, 95:1-12, 1952.

FRISCH, R.E. A method of prediction of age menarche from height and weight at ages 9 through 13 years. Pediatrics, Springfield, 53:384-90, 1974.

Control of the onset of puberty. Pediatrics, Springfield, 50:445, 1972.

Fatness of girls from menarche to age 18 years with a normogran. Hum. Biol, Detroit, 48: 353-9, 1976.

Influence on age of menarche. Lancet, London, 2:1007-8, 1973.

Pubertal adipose tissue: is it necessary for normal sexual maturation? Evidence from the rat and human female. Fed. Proc., Washington, 39:2395 400, 1980.

Weight at menarche: similarity for well nourished girls at differing ages and evidence for historical constancy. Pediatrics, Spring field, 50:445-50, 1972.

FRISCH, R.E. \& Mc ARTHUR, J. Menstrual cycles: fatness as a determinant of minimal weight and adolescent events. Science, Washington, 185:949, 1974.

FRISCH, R.E. \& REVELLE, R. Components of weight at menarche and the initiation of the adolescence. Hum. Biol., Detroit, 45:469-483, 1973.

Height and weight at menarche and a hipothesis of critical body weights and adolescents events. Science, Wa shington, 169:397-399, 1970.

Height and weight at menarche and a hypothesis of menarche. Arch Dis. Child., London, 46:695-701, 1971.

FRISCH, R.E.; REVELLE, R.; COOK, S. Components of critical weight at menarche and at initiation of the adolescent spurt: estimated total water, lean body mass and fat. Hum. Biol, Detroit, 45:469, 1973.

KENNEDY, G.C. Interactions between feeding behavior and hormones during growth. Ann. N.Y. Acad. Sci., New York, 157:1049-1061, 1969.

KENNEDY, G.C. \& MITRA, J. Body weight and food intake as initiating factors for puberty in the rat. J. Physiol., London, 166:408-418, 1963.

MATTOS, L.U.; KAJIYAMA, H.; MEGRICH, E.; KNOCH, M.; STEUER, R. Velocidade de crescimento e desenvolvimento sexual de ratas submetidas a diferentes graus de restrição alimentar. Rev. Esc. Enf. USP, São Paulo, 18(2):121-8, 1984.

NIMROD, R. \& RYAN, K.J. Aromatization of androgens by human abdominal and Breast fat tissue. J. Clin. Endocr., Springfield, 40:367-377, 1975.

PARIZKOVA, J. Impact of age diet and exercice on man's body composition. Ann. N.Y. Acad. Sci., New York, 110:661-674, 1963.

WIDDOWSON, E.M. \& Mc CANCE, R.A. Some effects of acelerating growth. Proc. Roy. Soc., London, 152:188-206, 1960.

WILEN, R. \& NAFTOLIN, F. Age and weight gain in the individual pubertal female - Rhesus Monkey (Macaca mulatta). Biol. of Repr., New York, 15:356-360, 1976.

WILEN, R. \& NAFTOLIN, F. Pubertal food intake and body weight and composition in the feed-restricted female rat: comparison with well fed animals. Pediat. Res., Basel, 12:263-267, 1978. 